\section{Asthma hospitalisations and air pollution}

\author{
B Barratt, ${ }^{1}$ J K Quint ${ }^{2}$
}

There has been significant interest in recent years on the effect of the environment on respiratory health and fairly consistent evidence that air pollution and temperature are somehow associated with asthma symptoms. However, studies have varied in the relationships found, with some suggesting high and others low temperature associations with asthma morbidity. $^{1-3}$ Several air pollutants, such as particulate matter, $\mathrm{NO}_{2}$ and $\mathrm{O}_{3}$, have been inconsistently associated with asthma and inevitably temperature confounds associations between asthma and pollutants. ${ }^{24}$ In addition, ambient temperature, particularly in temperate climates, may affect dry powder inhaler drug stability, and this may inadvertently confound worsening asthma control in areas of high humidity and high temperature, such as Hong Kong. 56

So while assessing the liaison between meteorological factors and asthma hospitalisations is not new, few studies have had sufficient statistical power to differentiate the effect of exposures on differing populations; that is children, adults and the elderly in a subtropical climate and in a city such as Hong Kong. With climate change an evolving phenomenon that will not go away, and increasing interest in disease 'splitting' as opposed to 'lumping' with respect to pathophysiology and phenotypes, it is imperative to understand more fully how global warming will influence air quality and thus respiratory health.

Hong Kong has a long and rich history of environmental epidemiological studies, fed by a densely packed ethnically homogenous population, comprehensive meteorological and air pollutant monitoring network and a systematically maintained central hospital records database. These resources have been used to their full potential by Lam et $a l^{7}$, whose time

\footnotetext{
${ }^{1}$ Analytical \& Environmental Sciences Division, King's College London, London, UK; ${ }^{2}$ Department of Respiratory Epidemiology, Occupational Medicine and Public Health, National Heart and Lung Institute, Imperial College London, London, UK

Correspondence to Dr J K Quint, Respiratory Epidemiology, Occupational Medicine and Public Health, National Heart and Lung Institute, Emmanuel Kaye Building, Imperial College London, London SW3 6LR, UK; j.quint@imperial.ac.uk
}

series analysis evaluates associations between asthma hospitalisations and meteorological factors in Hong Kong over a 7-year time period. They found that in the hotter season, hospitalisations were lowest at $27^{\circ} \mathrm{C}$, peaked at $30^{\circ} \mathrm{C}$ and then plateaued between $30^{\circ} \mathrm{C}$ and $32^{\circ} \mathrm{C}$. Whereas in the cold season, temperature was negatively associated with asthma hospitalisations. Adult admissions were most sensitive to temperatures in both seasons and admissions among children below five least associated. With regard to other factors, higher humidity and ozone levels in the hot season, and low humidity in the cold season were also associated with more asthma admissions. So why is it that different populations are affected by the environment in different ways? Does susceptibility to the environment differ in different age groups or is asthma as a disease physiologically or phenotypically different in each of these groups?

Hong Kong is unique in a number of ways that may influence the interpretation of results. During the cool season, northerly winds transport heavily polluted air from the urban and industrial regions of the Pearl River Delta in mainland China across the territory. Conversely, the hot season is characterised by fresh maritime winds, which bring the monsoon rains. So, as the temperature rises, the air clears and mean ozone levels fall. While many studies in temperate climates struggle to separate the effects of temperature and ozone on asthma admissions due to a close correlation, this is less true in this subtropical region. It is therefore interesting to note that the relatively low mean ozone levels in the hot season were significantly associated with admissions in adults and the elderly, but higher ozone levels during the cool season were not (although the authors note that the number of high ozone episodes was greater during the hot season).

The population of Hong Kong is also notoriously vertical, with a majority living well above street level in high rise buildings. This raises questions about the relevance of using one central monitoring station to represent meteorological conditions in Hong Kong, the authors arguing this was a deliberate decision as it is here that data are most complete. While temperatures across a relatively small urban area may be largely homogenous in open locations (such as parks and rooftops where meteorological stations tend to be sited), Hong Kong has a wellrecognised problem with micro-level daytime heat island effects in residential developments. Therefore, exposure misclassification could lead to bias in results if linked to age group.

The authors concluded that asthmatics should avoid exposure to adverse conditions by limiting outdoor activities in periods of extreme temperatures, particularly combinations of high humidity and high temperature, low humidity and low temperature and high ozone levels. But are these conclusions valid given the ecological association of the data? There is also the question of transferability of results. What is felt to be an extremely cold day to a long-term resident of a subtropical city would barely register as chilly to someone raised in temperate climates, and vice versa. It's 'As you like it'.

So to what degree can adaptation allow such relative terms as 'hot' and 'cold' to be used to compare studies in diverse climates? Are we any clearer as to what public health advice should be given to asthmatics of different ages relating to environmental conditions? Perhaps, perhaps not, but as focus shifts from Western to Eastern populations and their relationship with the environment, we can only expect detailed evidence such as that produced by Lam et al to increase in volume.

So alas, more questions than answers, but this analysis demonstrates the importance of and the need for a breadth of studies across geographically diverse regions of the world. To finish in the words of Shakespeare, "All the world's a stage, And all the men and women merely players" $(2.7 .139-40){ }^{8}$ maybe the same is true of air pollution and asthma hospitalisations and until we learn to better control our environment, we will dance to its tune.

Contributors The editorial was written and approved by $\mathrm{BB}$ and JKQ.

Competing interests None declared.

Provenance and peer review Commissioned; externally peer reviewed.

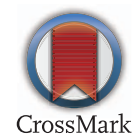

To cite Barratt B, Quint JK. Thorax 2016;71:10761077.

Published Online First 22 September 2016 


\section{Editorial}

\section{(5) Linked}

http://dx.doi.org/10.1136/thoraxjnl-2015-208054

Thorax 2016;71:1076-1077.

doi:10.1136/thoraxjn-2016-209009

\section{REFERENCES}

1 Zhang $Y$, Peng L, Kan $\mathrm{H}$, et al. Effects of meteorological factors on daily hospital admissions for asthma in adults: a time-series analysis. PLoS ONE 2014;9:e102475.

$2 \mathrm{Xu} \mathrm{Z}$, Huang C, Hu W, et al. Extreme temperatures and emergency department admissions for childhood asthma in Brisbane, Australia. Occup Environ Med 2013;70:730-5.

3 Qiu H, Yu IT-S, Tse LA, et al. Greater temperature variation within a day associated with increased emergency hospital admissions for asthma. Sci Total Environ 2015;505:508-13.

4 Guo Y, Jiang F, Peng L, et al. The association between cold spells and pediatric outpatient visits for asthma in Shanghai, China. PLoS ONE 2012;7: e42232.
5 Kwok PCL, Chan HK. Effect of relative humidity on the electrostatic charge properties of dry powder inhaler aerosols. Pharm Res 2008;25:277-88.

6 Borgstrom L, Asking L, Lipniunas P. An in vivo and in vitro comparison of two powder inhalers following storage at hot/humid conditions. J Aerosol Med 2005; 18:304-10.

7 Lam HC, Li AM, Chan EY, et al. The short-term association between asthma hospitalisations, ambient temperature, other meteorological factors and air pollutants in Hong Kong: a time-series study. Thorax 2016;71:1097-1109.

8 Shakespeare W. As You Like It. 1623. 